\title{
PUBLICADO EN THE JOURNAL OF MATHEMATICAL BEHAVIOR
}

Fernández, C., De bock, D., Verschaffel, L. \& Van Dooren, W. (2014). Do students confuse dimensionality and "directionality"? The Journal of Mathematical Behavior, 36, 166-176.

HTTP://DX.DOI.ORG/10.1016/J.JMATHB.2014.07.001 


\title{
DO STUDENTS CONFUSE DIMENSIONALITY AND “DIRECTIONALITY”?
}

\author{
Ceneida Fernández ${ }^{\mathrm{a}}$, Dirk de Bock ${ }^{\mathrm{b}}$, Lieven Verschaffel ${ }^{\mathrm{b}}$, \& Wim Van Dooren ${ }^{\mathrm{b}}$ \\ ${ }^{\mathrm{a} U n i v e r s i t y ~ o f ~ A l i c a n t e ~(S p a i n) ~}$ \\ ${ }^{\mathrm{b}}$ University of Leuven (Belgium)
}

Ceneida Fernández (corresponding author)

Ceneida.fernandez@ua.es

Departamento de Innovación y Formación Didáctica. Universidad de Alicante. Ap. de Correos, 99. 03080. Alicante. España. Tel: +34965903400 ext. 2028.

Dirk de Bock

Dirk.debock@kuleuven.be

KU Leuven, Faculty of Economics and Business, Center for Business Management Research, Warmoesberg 26, B-1000 Brussels, Belgium, Tel: +3216604250.

Lieven Verschaffel

Lieven.verschaffel@ppw.kuleuven.be

KU Leuven, Faculty of Psychology and Educational Sciences, Center for Instructional Psychology and Technology, Dekenstraat 2 - box 3773, B-3000 Leuven, Belgium, Tel: +3216326258 .

Wim Van Dooren

Wim.vandooren@ppw.kuleuven.be

KU Leuven, Faculty of Psychology and Educational Sciences, Center for Instructional Psychology and Technology, Dekenstraat 2 - box 3773, B-3000 Leuven, Belgium, Tel: +3216325755 .

\begin{abstract}
The aim of this research is to understand the way in which students struggle with the distinction between dimensionality and "directionality" and if this type of potential confusion could be a factor affecting students' tendency towards improper linear reasoning in the context of the relations between length and area of geometrical figures. 131 9th grade students were confronted with a multiple-choice test consisting of six problems related to the perimeter or the area of an enlarged geometrical figure, then some interviews were carried out to obtain qualitative data in relation to students' reasoning. Results indicate that more than one fifth of the students' answers could be characterized as based on directional thinking, suggesting that students struggled with the distinction between dimensionality and "directionality". A single arrow showing one direction (image provided to the students) seemed to strengthen the tendency towards improper linear reasoning for the area problems. Two arrows showing two directions helped students to see a quadratic relation for the area problems.
\end{abstract}

Keywords. Dimensionality, linear reasoning, area and perimeter, secondary level. 


\section{INTRODUCTION}

We report a study aimed at expanding our scientific knowledge on a systematic error that is committed by numerous students of a variety of ages in very diverse mathematical and scientific domains, namely the unwarranted application of proportionality or linearity in non-linear problem situations, a tendency sometimes referred to as the "illusion of linearity" (Van Dooren, De Bock, Janssens, \& Verschaffel, 2008). Research has shown that this tendency is persistent to change by instruction. Van Dooren, De Bock, Hessels, Janssens, and Verschaffel (2004) developed and implemented a lesson series with the aim to break 9th graders' tendency to give linear responses in non-linear situations, more specifically in the context of the relationships between the linear measures of a figure and its perimeter, area and volume. They found that non-linear relations and the effect of enlargements on area and volume remained intrinsically difficult and counterintuitive for many students even after extensive instructional attention.

However, in the same study, it was shown that students who, by the end of the lesson series, finally understood that the length-area relationship is quadratic, suddenly started to doubt about the nature of the linear length-perimeter relationship. The authors exemplified this with a striking question raised by a student in the final lesson:

"I really do understand now why the area of a square increases 9 times if the sides are tripled in length, since the enlargement of the area goes in two dimensions. But suddenly I start to wonder why this does not hold for the perimeter. The perimeter also increases in two directions, doesn't it?" (Van Dooren et al., 2004, p. 496).

This quote suggests that the student struggled with the distinction between dimensionality and "directionality" (the perimeter of a square is one-dimensional, but it has two "directions"). Of course, "directionality" is not a genuine mathematical term, but we use it for referring to the 
different directions a geometrical (plane) figure can have. For example, a triangle has three directions, a square has two directions (if we assume that parallel sides have the same direction), and a regular pentagon has five directions. In this study we investigate if the potential confusion between dimensionality and "directionality" could be a factor affecting students' tendency towards improper linear reasoning.

In the next section we first present an overview of the literature on the illusion of linearity. We focus on the domain of geometry where previous studies have evidenced that students tend to treat the relations between length and area or between length and volume as linear instead of, respectively, quadratic and cubic. Second, we summarize the scarce literature on the concept of dimensionality since it plays an important role in the principle governing the relation between the perimeter and the area of an enlarged or reduced geometrical figure. Although studies on this concept are rare, it is shown that students commonly struggle with understanding dimensionality.

\section{THEORETICAL AND EMPIRICAL BACKGROUND}

\subsection{The illusion of linearity}

Linearity is a powerful tool to model real-life situations, even if these situations are only approximately linear. For that reason, one major goal of mathematics education at all levels is to obtain both procedural fluency and conceptual understanding of linearity in its variety of forms and applications (Cramer, Post, \& Currier, 1993; Kalchman, \& Koedinger, 2005). However, the educational attention that goes to linearity at numerous occasions in students' school careers, along with the intrinsically simple and intuitive nature of the linear model (Rouche, 1989), has a serious drawback: It may lead to a tendency in students to see and apply linearity anywhere, thus also in situations that are not linear at all. Already in 1983, Freudenthal 
warned for that pitfall: "Linearity is such a suggestive property of relations that one readily yields to the seduction to deal with each numerical relation as though it were linear" (p. 267).

Examples of the misuse of linearity can be found at different age levels and in various mathematical and scientific domains (Fernández, Llinares, Van Dooren, De Bock, \& Verschaffel, 2012; for a review, see Van Dooren, De Bock, Janssens, \& Verschaffel, 2008). For instance, in a study on arithmetic word problems solving by Cramer, Post and Currier (1993), 32 out of 33 pre-service elementary school teachers answered by means of a proportion $(9 / 3=x / 15)$ to the problem "Sue and Julie were running equally fast around a track. Sue started first. When she had run 9 laps, Julie had run 3 laps. When Julie completed 15 laps, how many laps had Sue run?" More recently, Van Dooren, De Bock, Hessels, Janssens, and Verschaffel (2005) observed that Flemish primary school pupils' performance on linear word problems considerably improved from 3rd to 6th grade. But they also observed that during the same period, pupils' tendency to over-use linear methods to non-linear problems increased accordingly: Whereas in 3rd grade $30 \%$ of all non-linear problems were solved linearly, this percentage increased until $51 \%$ in 6th grade. This tendency has been confirmed by Fernández, Llinares, Van Dooren, De Bock, and Verschaffel (2011) with Spanish secondary school students: Whereas 7th and 8th grade students were more successful in solving non-linear problems, 9th and 10th grade students were more successful in solving linear ones.

Furthermore, a (re-)analysis of both well-known and less-known probabilistic misconceptions by Van Dooren, De Bock, Depaepe, Janssens, and Verschaffel (2003) showed that these are often interpretable in terms of improper applications of linearity. A typical example is students' belief that the probability of at least one success in a game of chance is directly proportional to the number of trials. In the domain of calculus, an example of the over-use of linearity related to university students was provided by Esteley, Villarreal, and Alagia (2004): 62\% of students involved in a first calculus course responded linearly with respect to the increase of the height 
as a function of time, instead of taking into account the exponential character of this growth process in the problem: "If a plant measures $30 \mathrm{~cm}$ at the beginning of an experiment, and its height increases 50\% monthly, how much will it measure after 3 months?".

This paper focuses on students' misuse of linearity in geometry. In this domain, one of the best-known and most frequently investigated cases relates to application problems about the effect of an enlargement or reduction of a figure on its area or volume. The principle governing this type of problems is that an enlargement or reduction with factor $k$ enlarges all lengths (and thus also the perimeter) with factor $k$, the area with factor $k^{2}$, and - for a solid - the volume with factor $k^{3}$. A crucial aspect in understanding this principle is the insight that these factors only depend on the dimensions of the magnitudes involved (length, area, and/or volume) and not on the type of figure (square, triangle, circle, cube,...). When the sides of a triangle are tripled, the perimeter of the triangle is tripled too, but its area is multiplied by 9. According to Freudenthal (1983), this mathematical principle is "so fundamental, that, phenomenologically and didactically, it should be put first and foremost. This fact rather than formulae for circumferences, areas and volumes, should be primary” (p. 267).

\subsection{Empirical research within the domain of geometry}

During the last two decades, students' tendency to treat relations between length and area or between length and volume as linear instead of, respectively, quadratic and cubic, has been extensively studied (e.g., De Bock, Verschaffel, \& Janssens, 1998; Gagatsis, Modestou, Elia, \& Spanoudes, 2009; Modestou, Gagatsis, \& Pitta-Pantazi, 2004; Tierney, Boyd, \& Davis, 1990). Tierney et al. (1990) observed in their research on the area concept in prospective elementary school teachers that "in responding to questions about the effect of halving or doubling the lengths of the sides of a square, most students said that the area was also halved or doubled" (p. 308). 
In two exploratory studies by De Bock et al. (1998), 7th and 10th grade students were administered paper-and-pencil tests with linear and non-linear word problems related to lengths, perimeters and areas of different types of plane figures (squares, circles, and irregular figures). An example of a (non-linear) area problem is the following: "Farmer Carl needs four hours to fertilise a square piece of land with a side of $200 \mathrm{~m}$. How many hours would he approximately need to fertilise a square piece of land with a side of $600 \mathrm{~m}$ ?" More than $90 \%$ of the 7 th graders and more than $80 \%$ of the 10th graders failed on area problems because they applied linear methods. It was also observed that the type of geometrical figure involved in the problem had an influence on the tendency to give linear answers: Students performed better on problems about a regular figure than on problems about an irregular figure.

Gagatsis et al. (2009) presented geometrical word problems concerning the perimeter, area and volume of different figures to 653 students of grades 9 and 10. Problems were presented in three groups and each group of problems was accompanied by a given number. Students had to choose the problem that was appropriate for the given number. Each group of problems consisted of one "appropriate-usual problem", which was appropriate for the given number, one "pseudo-proportional problem", where linear reasoning would lead to the given number, and one "unusual problem", which had many solutions. Results showed a strong tendency in the 9th grade students to apply linearity. For these students the pseudo-proportional problems were almost of the same nature as the appropriate-usual problems. However the 10th grade students started to differentiate their ways of interpreting and understanding this kind of problems.

Other studies focussed on attempts to break the "illusion of linearity". The intervention study by Van Dooren et al. (2004) that was already mentioned in the introduction has shown that even after instruction, the illusion remains a persistent obstacle for many students. By the end of a concentrated and systematic instructional action, some students who finally understood that the 
length-area relationship is quadratic, suddenly started to doubt about the nature of the linear length-perimeter relationship, likely because of their struggling with the distinction between dimensionality and "directionality" (see the quote in the introduction). Therefore, we wondered if the confusion between dimensionality and "directionality" could be a factor affecting students' tendency towards improper linear reasoning. In the next section we present a theoretical and empirical background related to the concept of dimensionality.

\subsection{Dimensionality}

Although dimensionality is crucial to many parts of mathematics and science, research about this concept is rare. Freudenthal (1983) stated that "dimension is an indispensable tool if magnitudes and their mutual relations are at stake" (p. 266). He pointed out that in measuring magnitudes it is critical to know what kind of magnitudes they are (length, area, volume...), and at this point the dimension has an important role: What dimensions does the object to be measured have? Moreover, it should be stressed for didactical reasons that "the behavior of geometric measures under geometrical multiplication depends on the dimension" (p. 267).

Area measurement is particularly interesting because it involves the coordination of two dimensions. There is extensive evidence that both primary and secondary school students have inadequate understanding of area and area measurement. For example, Carpenter et al. (1988) showed that almost half of a sample of 7 th grade students could calculate the area of a rectangle when given both dimensions; however, only $13 \%$ applied their knowledge of the area formula to a square, even when they knew that the sides of a square are equal. Anderson and Cuneo (1978) concluded from their experiments that 5-year-old children use an adding rule to calculate perceived area from perceived height and width. In this erroneous rule for judging area (height + width rule), the two dimensions are combined additively instead of multiplicatively. 
The experiential origin of the area formula is the action of physically covering a rectangle with unit squares. But whereas this action is one-dimensional and involves an iterative additive process, the formula is two-dimensional and multiplicative. Outhred and Mitchelmore (1996) showed that when students were drawing squares (the unit to measure the rectangle's area) to cover a rectangle, many first graders did not see the importance of joining the units so that there were no gaps, and drew units individually. Until students began to join the units in two dimensions, they did not usually align rows and columns. Before drawing arrays using only lines, some students drew lines across the width of the rectangle to indicate rows and marked off the units in each row individually while others drew some individual units (usually the top row and the left column) as a guide for drawing the array. So, drawing lines in one dimension appeared to be a precursor to recognise rows as composite units. Such recognition helped students to perceive that squares could be constructed by joining lines in the other direction, and hence realise the two-dimensional structure of an array. In another study, Outhred and Mitchelmore (2000) focused on understanding the relationship between the size of the array and the linear dimensions of the rectangle in which it is enclosed. They found that, although the fact that the number of units in the array must depend on the measurements of the sides may seem self-evident to adults, it is clearly not obvious to children.

Mathematics education researchers have suggested that understanding area measurement and interpreting the area formula for a rectangle presumes multiplicative reasoning about the two lengths (Battista, Clements, Arnoff, Battista, \& Van Auken Borrow, 1998). Huang (2010) concluded that young students do not seem to completely comprehend the meanings of the operation of multiplication and this weakness may hinder students' further understanding of the area formula for a rectangle. Therefore, it is noteworthy that to understand an array structure, which is generated from the process of iterating a square unit on the region of a rectangle, an 
advanced connection between the work of tiling the dimensions of a rectangle to rectangular arrays and multiplication is required (Huang, 2010, p. 119).

\subsection{Problem statement}

There is quite some evidence showing that students struggle to understand dimensionality. A major claim underlying the present study is that one reason for that struggle is that students confuse the dimensions of an object or magnitude with its "directions". As we said in the introduction section, we use the term "directionality" for referring to the different directions a geometrical plane figure can have. For instance a square has two directions (if we assume that parallel sides have the same direction) but the perimeter is one-dimensional. We have not encountered any previous research making this claim. Therefore, in this study, we will empirically investigate the existence and impact of this potential confusion.

So, the aim of this research is to unravel the extent to which and the way in which students struggle with the distinction between dimensionality and "directionality" and how this may affect their tendency towards improper linear reasoning in the context of the relations between length and area of enlarged geometrical figures.

\section{METHOD AND HYPOTHESES}

For the purpose of this study, a collective paper-and-pencil test was administered to 131 9th grade secondary school students (14-15-years-olds) from four Spanish schools. To obtain qualitative information on students' reasoning, we afterwards conducted individual interviews of 21 new and randomly chosen 9th grade students from three different schools. These interviews were audiotaped. As we applied a multiple-choice response format for the test problems, without asking any justification, the interviews provided us with valuable information about students' reasoning processes. 


\subsection{Design of the paper-and-pencil test}

The test consisted of six problems related to the perimeter and the area of an enlarged figure: Two problems were about an equilateral triangle (one related to its perimeter and the other to its area), two problems were about a square (again, one related to its perimeter and the other to its area), and two problems were about a regular pentagon (again, one related to its perimeter and the other to its area). For each problem, students had to choose the correct answer from three given alternatives. Independent of whether it was an area or a perimeter problem, each problem was accompanied with the same answer alternatives. The first and second alternatives (alternatives $\mathrm{a}$ and $\mathrm{b}$ in the test) were selected taking into account the common difficulties of students when they relate lengths and areas and the third (alternative c) was selected taking into account the idea of "directionality".

- Alternative a (linear) was based on the linear reasoning that if the sides of a figure are doubled, the perimeter is doubled (correct) and the area is doubled too (incorrect).

- Alternative b (quadratic) was based on the claim that if the sides of a figure are doubled, student may think that the perimeter is multiplied by four (incorrect) and the area too (correct).

- Alternative c (directional) was based on the idea of directionality. For instance, if the sides of an equilateral triangle are doubled (three directions), the perimeter or area of the enlarged figure will become $3 \times 2=6$ times larger (incorrect).

Problems were formulated in a missing-value format, just like in previous investigations on students' improper linear reasoning (De Bock et al., 1998; Fernández et al., 2012) and we asked for the perimeter or the area in an indirect way, i.e. by using a variable that is proportionally related to the perimeter or area. Previous research elicited no significant differences between 
students' performance on proportional or non-proportional problems involving direct or indirect measures (Van Dooren, De Bock, De Bolle, Janssens, \& Verschaffel, 2003). Furthermore in all problems we used regular figures. Examples of the two items about an equilateral triangle are given in Figure 1.

\begin{tabular}{|l|l|}
\hline & $\begin{array}{l}\text { Choose the correct option } \\
\text { The weight of an iron fence around a lawn in the } \\
\text { form of an equilateral triangle with a side of } 8 \mathrm{~m} \text { is } \\
300 \mathrm{~kg} \text {. Then the weight of an iron fence of the same } \\
\text { type around a lawn in the form of an equilateral } \\
\text { triangle with a side of } 16 \mathrm{~m} \text { is approximately } \\
\text { a) } 300 \times 2=600 \mathrm{~kg}\end{array}$ \\
b) $300 \times 2^{2}=1200 \mathrm{~kg}$ \\
c) $300 \times 3 \times 2=1800 \mathrm{~kg}$
\end{tabular}

Figure 1: Area and perimeter problems related with the equilateral triangle

As we were interested in how "directionality" would affect students' answers, we designed three different versions of the test (test conditions): D1, D2, and D3. Each test condition differed with respect to the images that were shown to the students. In the D1 condition, one arrow with two heads was provided (Figure 1). In the D2 condition, two double-headed and perpendicularly oriented arrows were provided and, finally, in the D3 condition no arrows were given (Figure 2). Our hypotheses were, first, that the single arrow in the D1 condition might help students to apply a linear relation for the perimeter problems (Hypothesis 1A), but might at the same time strengthen the tendency towards improper linear reasoning for the area problems 
(Hypothesis 1B). Second, we hypothesized that the two arrows in the D2 condition might help students to apply the quadratic relation for the area problems (Hypothesis 2A), but put them on the wrong track for the perimeter problems (Hypothesis 2B). Third, in the D3 condition, because of the absence of any extra arrow(s), only the different directions in the figure might lead to responses in which the number referring to these different directions is used (Hypothesis 3). Fourth, we wondered if the type of figure (triangle, square, or pentagon) would have an effect on the occurrence of directional answers.

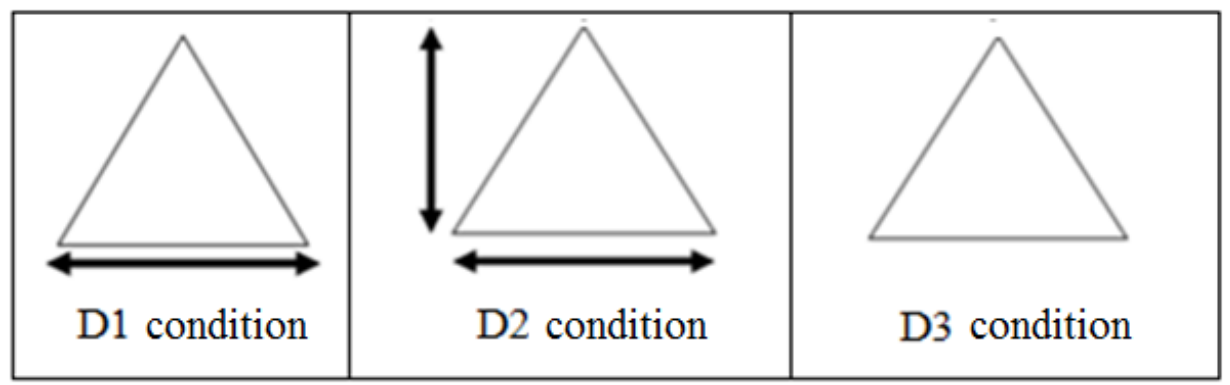

Figure 2: Images given in the different versions of the test (test condition)

Participants were randomly divided in the three test conditions: Forty-three participants answered the D1 version of the test, 44 the D2 version, and 44 the D3 version. In each condition, problems were put in six different orders. The three versions of the tests as well as the different orders were randomly distributed among the participants. Students received between 10 and 15 minutes to complete the test, which was sufficient for all of them.

\subsection{Design of the interview}

The interview consisted of three phases. In the first phase, the 21 students who participated in the interview had to solve individually the paper-and-pencil test described in section 3.1 , and immediately afterwards they were asked to provide justifications for their answers to the six problems (second phase). Seven participants were interviewed with the D1 version, seven with the D2 version, and seven with the D3 version of the test. After the student had provided the 
requested justifications, the third phase proceeded in two different ways depended on how they behaved in phase 2 :

- If the student had not provided any directional justification, we tried to get more explicit information about his thinking by confronting him with the answer of another student: "A classmate has chosen alternative c for this problem, do you think it is correct?" and, if he answered negatively, we proceeded with a follow-up question: "Why do you think this classmate has chosen that alternative?". We asked these questions for all six items.

- If the student had provided directional justifications, we gave him two extra problems (one area and one perimeter problem) using a new geometrical figure: a parallelogram where the number of dimensions (two dimensions) coincides with the number of directions (two directions). These extra problems were given in the format of the test that the student had previously solved (D1, D2 or D3 version). In Figure 3 we show the perimeter problem for the D1 version.

\begin{tabular}{|l|l|}
\hline & $\begin{array}{l}\text { Choose the correct option } \\
\text { The weight of an iron fence around a lawn in the form } \\
\text { of a parallelogram with sides of } 6 \mathrm{~m} \text { and } 5 \mathrm{~m} \text { is } 300 \mathrm{~kg} . \\
\text { Then the weight of an iron fence of the same type } \\
\text { around a lawn in the form of a parallelogram with sides } \\
\text { of } 18 \mathrm{~m} \text { and } 15 \mathrm{~m} \text { is approximately }\end{array}$ \\
a) $300 \times 3=900 \mathrm{~kg}$ \\
b) $300 \times 3^{2}=2700 \mathrm{~kg}$ \\
c) $300 \times 2 \times 3=3600 \mathrm{~kg}$
\end{tabular}

Figure 3: Perimeter problem about a parallelogram (D1 condition of the test) 


\subsection{Analysis}

The answers from group of 131 9th grade secondary school students on the collective paper-and-pencil test were classified as linear (if a student chose alternative a), as quadratic (if a student chose alternative b), or as directional (if a student chose alternative c). Results were statistically analysed by means of a repeated measures logistic regression analysis using the generalized estimating of equations (GEE).

Data from the 21 interviews were analysed descriptively and qualitatively, since the limited number of participants in the three interview conditions did not allow a systematic statistical analysis. All interviews were transcribed and then, we selected and analysed the transcripts in which students gave justifications for directional answers. The main goal of the interviews was to provide us with qualitative information about the nature of students' directional reasoning. Particularly, these data were meant to support the results obtained from the statistical analysis of the test results and for providing us with fine-grained information about students' confusion between dimensionality and "directionality".

\section{RESULTS}

We first present the results of the statistical analysis describing the general trends in students' success rates on the perimeter and area problems in each test condition; presenting the effects of the test condition on linear, quadratic and directional answers and linking these results to our three hypotheses; and discussing the effect of the type of figure on linear, quadratic and directional answers. Second we present the results obtained from the interviews. 


\subsection{Results of the collective paper-and-pencil test}

\subsubsection{Description of the general trends}

Table 1 shows the percentages of students' correct answers for each type of problem and test condition. Students were generally much more successful on perimeter problems $(66.8 \%)$ than on area ones $(15.2 \%)$. The repeated measures logistic regression analysis revealed that the variable type of problem (area or perimeter problems) had a significant main effect on students' success showing that this difference was significant, $\chi^{2}(1, N=131)=53.843, p<0.001$, in the sample as a whole as well as in each of the three test conditions. Although there was not a significant type of problem and test condition interaction effect, $\chi^{2}(2, N=131)=1.521, p=0.467$, Table 1 suggests that students were more successful on area problems in the D2 condition (18.2\%) than on area problems in the D1 condition (10.8\%) and in the D3 condition (16.7\%).

Table 1. Percentages of students' correct answers for each type of problem (A= Area problems, $\mathrm{P}=$ Perimeter problems) and test condition (D1, D2, and D3)

\begin{tabular}{cccc}
\hline & D1 & D2 & D3 \\
\hline $\mathrm{A}$ & 10.8 & 18.2 & 16.7 \\
& $\wedge$ & $\wedge$ & $\wedge$ \\
$\mathrm{P}$ & 60.5 & 62.1 & 78.0 \\
\hline
\end{tabular}

\subsubsection{Effects of test condition on linear, quadratic and directional answers}

Table 2 shows the percentages of linear, quadratic, and directional answers for the three test condition. Results clearly confirm students' tendency towards improper linear reasoning. As shown in Table 2, $66.7 \%$ of the answers on the area problems in the D1 condition, $57.6 \%$ of the answers on the area problems in the D2 condition, and $65.9 \%$ of the answers on the area problems in the D3 condition were linear ones. 
Table 2. Percentages of linear, quadratic and directional answers in the three test condition (correct answers are in bold).

\begin{tabular}{lccccccccc}
\hline & \multicolumn{3}{c}{ D1 } & \multicolumn{4}{c}{ D2 } & \multicolumn{3}{c}{ D3 } \\
\hline Answer & P & A & Total & P & A & Total & P & A & Total \\
\hline Linear & $\mathbf{6 0 . 5}$ & 66.7 & 63.6 & $\mathbf{6 2 . 1}$ & 57.6 & 59.8 & $\mathbf{7 8 . 0}$ & 65.9 & 72.0 \\
Quadratic & 17.0 & $\mathbf{1 0 . 8}$ & 13.9 & 11.4 & $\mathbf{1 8 . 2}$ & 14.8 & 7.6 & $\mathbf{1 6 . 7}$ & 12.1 \\
Directional & 22.5 & 22.5 & 22.5 & 26.5 & 24.2 & 25.4 & 14.4 & 17.4 & 15.9 \\
\hline
\end{tabular}

As we hypothesized (Hypothesis 1B), the single arrow in the D1 condition seemed to strengthen the tendency towards improper linear reasoning: Students gave more linear answers on the area problems in the D1 condition $(66.7 \%)$ than on the area problems in the D2 condition (57.6\%), however pairwise comparisons showed that this difference was not significant $(p=0.147)$. Furthermore, and contrary to Hypothesis $1 \mathrm{~A}$, the D1 condition did not seem to help students to apply a linear relation for the perimeter problems: Students gave more linear answers on the perimeter problems in the D2 condition (62.1\%) and in the D3 condition (78\%) than on the perimeter problems in the D1 condition $(60.5 \%)$. So, the effect of the single arrow on the use of linear answers on the perimeter problems proved to be negative.

In contrast, the two double-headed arrows in the D2 condition seemed to be helpful to find the correct answer on the area problems: Students gave more quadratic answers on the area problems in the D2 condition (18.2\%) than on the area problems in the D1 condition (10.8\%) but, once again, this difference was not significant $(p=0.061)$ (Hypothesis 2A). Furthermore, the repeated measures logistic regression analysis revealed a significant type of problem (area vs. perimeter) and test condition (D1, D2, or D3) interaction effect on the incorrect choice for the quadratic answer, $\chi^{2}(2, N=131)=19.080, p<0.001$, due to the fact that students gave significantly less incorrect quadratic answers on the perimeter problems in the D2 condition $(11.4 \%)$ than on the perimeter problems in the D1 condition (17.0\%). So, contrary to 
Hypothesis 2B, the two doubled-headed arrows did not put students on the wrong track for the perimeter problems.

Furthermore, $21.3 \%$ of all answers were directional (mean of the three test condition; $22.5 \%$ in the D1 condition, $25.4 \%$ in the D2 condition, and $15.9 \%$ in the D 3 condition). Although this is not a high percentage, especially given that it was obtained in a multiple-choice testing setting, it suggests that in about one fifth of the cases participants may have struggled with the distinction between dimensionality and "directionality". However, contrary to our Hypothesis 3, this result was independent from the test condition, since the different ways in which the problems were presented in the three conditions did not significantly influence students' tendency to respond directionally $\left(\chi^{2}(2, N=131)=2.917, p=0.233\right)$. We will explore this further in the interview data.

\subsubsection{Effect of the type of figure on linear, quadratic and directional answers}

We also analyzed the effect of type of figure (triangle, square, or pentagon) on the occurrence of directional answers. Table 3 shows the percentages of linear, quadratic and directional answers for each of the three types of figures (there are no significant differences between the different test conditions).

Table 3: Percentages of linear, quadratic and directional answers for each figure

\begin{tabular}{lccc}
\hline & Linear & Quadratic & Directional \\
\hline Triangle & 68.32 & 19.85 & 17.56 \\
Square & 60.31 & 14.12 & 25.57 \\
Pentagon & 66.79 & 13.36 & 19.85 \\
\hline
\end{tabular}

The repeated measures logistic regression analysis showed that the variable type of figure (square, pentagon, or triangle) had a significant effect on the occurrence of directional answers, 
$\chi^{2}(2, N=131)=23.301, p<0.001$. Pairwise comparisons indicated that both the square-pentagon and the square-triangle difference were significant (while the pentagon-triangle difference was not significant): Students gave more directional answers for the square figure (25.57\%) than for the pentagon or triangle (19.85\% and $17.56 \%$, respectively).

\subsection{Results of the interview}

The answers of the 21 participants on the six problems of the paper-and-pencil test supported the results of the collective paper-and-pencil test with respect to the directional answer, since 10 out of the 21 interviewed students (two who were interviewed with the D1 version, four with the D2 version and four with the D3 version) strongly tended to the directional alternatives. Four of these 10 students always opted for the "directional" answer (on the area and perimeter problems for all the figures), three of them gave directional answers on the perimeter problems of all the figures, two of them gave directional answers on the perimeter problem about the square, and one gave directional answers on the perimeter and area problems about the square. So 37 of the 126 answers (21 students $\times 6$ problems) were directional (i.e., $29.4 \%$ of all answers). The remaining 11 students gave linear or quadratic answers.

Furthermore, students' explanations provided evidence supporting their struggle with the distinction between dimensionality and "directionality". The explanations of the 10 students who had chosen for alternative c (directional answer) in some (six students) or all problems (four students) were based on "the number of sides", referring to the number of directions (the justifications of all of the 37 directional answers), as illustrated in an interview excerpt of student A who chose alternative c (directional answer) for all problems:

Interviewer: Why did you choose alternative $c(6 \times 5 \times 2=60 \mathrm{~kg})$ for that problem? [Interviewer refers to the problem: To fertilise a piece of land in the form of a regular pentagon with a side of $60 \mathrm{~m}$, a farmer needs $6 \mathrm{~kg}$ of fertilizer. If the farmer has to 
fertilise a piece of land in the form of a regular pentagon with a side of $120 \mathrm{~m}$, the amount of fertilizer he will need is approximately...]

Student A: Because $120 \mathrm{~m}$ is the double of $60 \mathrm{~m}$. So we have to take the double of $6 \mathrm{~kg}$ and multiply this by the number of sides of the pentagon (five sides).

Interviewer: And why did you choose alternative c $(300 \times 3 \times 2=1800 \mathrm{~kg})$ in that problem? [Interviewer refers to the problem: The weight of an iron fence around a lawn in the form of an equilateral triangle with a side of $8 \mathrm{~m}$ is $300 \mathrm{~kg}$. Then the weight of an iron fence of the same type around a lawn in the form of an equilateral triangle with a side of $16 \mathrm{~m}$ is approximately...]

Student A: Because 16 is the double of 8 , so if the weight of an iron fence is $300 \mathrm{~kg}$ initially, we have to take the double and then multiply this by the three sides of the equilateral triangle.

Interviewer: And why did you choose alternative c $(200 \times 2 \times 3=1200 \mathrm{~kg})$ in that problem? [Interviewer refers to the problem: The weight of an iron fence around a lawn in the form of a square with a side of $6 \mathrm{~m}$ is $200 \mathrm{~kg}$. Then the weight of an iron fence of the same type around a lawn in the form of a square with a side of $18 \mathrm{~m}$ is approximately...]

Student A: Because 18 is the triple of 6, so if the weight of an iron fence is $200 \mathrm{~kg}$ initially, we have to take the triple and then multiply this by the two sides that the square enlarges".

Student A seems to think the perimeter's and the area's increase depends on the number of sides of that figure (different directions) instead of taking into account that the perimeter is a one-dimensional magnitude and the area is a two-dimensional magnitude.

Another illustration can be found in the following interview excerpt of student B who chose alternative c (directional answer) for the perimeter problems, but gave correct (quadratic) answers on the area problems.

Interviewer: why did you choose alternative c $(300 \times 3 \times 2=1800 \mathrm{~kg})$ ? [Interviewer refers to the problem: The weight of an iron fence around a lawn in the form of an equilateral triangle with a side of $8 \mathrm{~m}$ is $300 \mathrm{~kg}$. Then the weight of an iron fence of the same type around a lawn in the form of an equilateral triangle with a side of $16 \mathrm{~m}$ is approximately...]

Student B: As 16 is the double of 8, we have to multiply $300 \mathrm{~kg}$ by two and by three because the triangle has three sides. 
Interviewer: why did you choose alternative $b\left(6 \times 2^{2}=24 \mathrm{~kg}\right)$ ? [Interviewer refers to the problem: To fertilise a piece of land in the form of a regular pentagon with a side of $60 \mathrm{~m}$, a farmer needs $6 \mathrm{~kg}$ of fertilizer. If the farmer has to fertilise a piece of land in the form of a regular pentagon with a side of $120 \mathrm{~m}$, the amount of fertilizer he will need is approximately...]

Student B: You have to obtain the area is that the square meters so as 120 is the double of 60 , you have to multiply the $6 \mathrm{~kg}$ by $2^{2}$ to obtain the area of the new regular pentagon.

So, student B seems to understand that the area of a regular pentagon gets four times larger if the sides are doubled (because it has two dimensions (square meters)), but at the same time he seems to think that the perimeter's increase depends on the number of sides of that figure (different directions) instead of taking into account that the perimeter is a one-dimensional magnitude.

Furthermore, as explained in section 3.2, we made use of a new figure, the parallelogram, which also has two dimensions and "two directions". The four students who gave directional justifications on all six problems of the paper-and-pencil test also gave directional justifications on the problems (perimeter and area) about a parallelogram. The three students who only gave directional justifications on the perimeter problems of all the figures also gave a directional justification on the perimeter problem about the parallelogram. The two students who only gave directional justifications on the perimeter problem about the square also gave a directional justification on the perimeter problem about the parallelogram. Finally the student who only gave a directional justification on the perimeter and area problems about a square also gave directional justifications on the perimeter and area problems about a parallelogram. Therefore, all students who had given a directional justification on the problems about the square (perimeter or/and area) gave a directional justification on the problems about the parallelogram. So, students seem to give more directional answers on figures where the number of directions and dimensions coincide such as the square and the parallelogram. 
Finally we report the reactions of the 11 students who had answered the six problems linearly or quadratically and were confronted with the answer of another student: "A classmate has chosen alternative c (directional answer), do you think is it correct?" and "Why do you think this classmate has chosen that alternative?" All of them said that this answer was not correct, and the arguments of four of them about why this classmate had chosen alternative c (directional answer) were also explicitly based on the figure's directions. The other seven students could not explain why this classmate had chosen that answer. The next excerpt shows the explanation of student $\mathrm{C}$ who argued that this classmate based his answer on the (number of) sides of the figure.

Interviewer: You have chosen alternative a (linear answer) on this problem. Why? [Interviewer refers to the problem: The weight of an iron fence around a lawn in the form of a regular pentagon with a side of $9 \mathrm{~m}$ is $500 \mathrm{~kg}$. Then the weight of an iron fence of the same type around a lawn in the form of a regular pentagon with a side of $18 \mathrm{~m}$ is approximately...]

Student C: Because 18 is the double of 9, so the weight of the iron fence would be the double of $500 \mathrm{~kg}$ so $500 \mathrm{~kg}$ is multiplied by two.

Interviewer: A classmate has chosen alternative c. Do you think is this correct?

Student C: No.

Interviewer: Why do you think has this classmate chosen that answer?

Student C: Mmmm....because maybe she thinks that she has to multiply by all the sides that the figure enlarges.

Student $\mathrm{C}$ seems to understand that the perimeter of a regular pentagon gets two times larger if the sides are doubled because the perimeter is a one-dimensional magnitude. When we asked him if he thought that alternative $\mathrm{c}$ was correct, he responded negatively and explained that "maybe his classmate had multiplied by all the sides of that figure".

The results of the individual interviews endorsed the results obtained by the collective paper-and-pencil test with respect to directional thinking, since the interviewed students strongly tended to the directional alternatives and typically gave more directional answers on 
problems about figures for which the number of directions and dimensions coincide such as the square and the parallelogram. Furthermore, their explanations evidenced their struggle with the distinction between dimensionality and "directionality".

\section{CONCLUSIONS AND DISCUSSION}

Previous research has shown students' tendency to improperly apply linearity even after adequate instruction. However, it was reported that some students who finally understood that the length-area relationship is quadratic, suddenly started to doubt about the nature of the linear length-perimeter relationship (Van Dooren et al., 2004). So we wondered if these students struggled with the confusion between dimensionality and "directionality" and if that confusion could be a factor affecting students' tendency towards improper linear reasoning. The results of the present study, firstly, confirm a linear tendency in students' answers on problems involving length and area of similar plane figures, as observed in several previous studies (De Bock et al., 1998; Gagatsis et al., 2009; Modestou et al., 2004). However, even though previous studies have shown that a multiple-choice response format diminishes the tendency to respond linearly (Vlahovic-Stetic, Pavlin-Bernardic, \& Rajter, 2010), it seems that this alternative response mode did not radically break students' tendency to give linear responses on area problems.

Secondly, as we were interested in how "directionality" would affect students' answers, we designed three different versions of the test (D1, D2, and D3 condition) that differed in the way images were provided to the students (one arrow with two heads, two double-headed and perpendicularly oriented arrows, or no arrows, respectively). One of our hypotheses was that the single arrow (D1 condition) might help students to apply a linear relation for the perimeter problems, but might at the same time strengthen the tendency towards improper linear reasoning for the area problems. Results show that the single arrow with two heads (showing one direction) in the D1 condition seemed to strengthen the tendency towards improper linear 
reasoning (Hypothesis 1B): Students gave more linear answers on the area problems in the D1 condition than on the area problems in the D2 condition. However, it seems that it did not help students to apply a linear relation for the perimeter problems (Hypothesis 1A). Furthermore, we hypothesized that the two arrows in the D2 condition might help students to apply the quadratic relation for the area problems, but put them on the wrong track for the perimeter problems. Results indicate that the two arrows (showing two directions) in the D2 condition helped students to apply a quadratic relation for the area problems (Hypothesis 2A) since students gave more quadratic answers on the area problems in the D2 condition than on the area problems in the D1 condition. However, the two arrows did not put students on the wrong track for the perimeter problems: The D2 condition did not foster students to apply a quadratic relation for the perimeter problems (Hypothesis 2B). It appeared that the single arrow had a negative effect on students' answers since it did not help them to apply the linear answer on the perimeter problems and strengthened their tendency towards improper linear reasoning on the area problems. On the other hand, the two arrows had a positive effect on students' answers because it helped to apply a quadratic relation on the area problems and did not foster to apply a quadratic relation for the perimeter problems.

Thirdly, the statistical analysis did not show a significant effect of the test condition or a significant interaction effect of type of problem (area/perimeter) and test condition on students' choice for the directional answer. So, contrary to Hypothesis 3 (in the D3 condition, because of the absence of any extra arrow(s), only the different directions in the figure might lead to responses in which the number referring to these different directions is used), students gave directional answers independently of the test version. However, about one fifth of the answers were directional, suggesting that in a significant number of cases students struggled with the distinction between dimensionality and "directionality". This latter result was confirmed by interview data, which clearly revealed that in a substantial number of cases $(29.4 \%$ of the 
answers), students' reasoning about why they had chosen the directional alternative was indeed based on "the number of sides of each figure" (referring to the directions of the figure). So, in these cases students' reasoning was focused on the "directions of the figure" instead of on the dimension of the perimeter (one-dimensional) or the area (two-dimensional).

Finally, a main effect of the type of figure was observed: Students gave more directional answers on problems about a square than on problems about a pentagon or triangle. So, it seems that students struggle more with the distinction between dimensionality and "directionality" in figures where the number of directions and dimensions coincide. These are the cases of the square - and for the interview also the parallelogram - which have two dimensions but also "two directions". All students who had given a directional justification on the problems about the square (perimeter or/and area) gave a directional justification on the problems about the parallelogram during the interview. However, the issue "why some students only gave directional answers on the perimeter or/and area about the square and parallelogram" deserves further investigation.

In order to obtain more fine-grained information about students' directional reasoning, some other aspects of the current study deserve further investigation too. As we used a simple multiple-choice response format for the problems in which the directional answer was present, we may have elicited directional reasoning. So the question remains if students would also reason directionality if they were not offered this alternative as a possible answer. Another question relates to the images provided to students. In this study it seemed that the images did not influence students' directional reasoning. Would it happen if we did not provide any representation of the geometrical figures? So a "D4 condition" wherein any geometrical figure was provided could be added to our test. Finally, as the interview took place after students had solved the paper-and-pencil test, it could happen that students' verbalisations did not reflect their actual thinking during the solution of that test. At a more fundamental level, one could 
even raise the question if students would be able to verbalise their "directional" thinking at all, given that they may not have direct access to it. So it could be that the directionality in their thinking may play at an implicit level or that it may not have played at all, but be a post hoc rationalization.

The results of this study are relevant for educational practice. Since secondary school students tend to confuse between dimensionality and "directionality", it is a challenge for their teachers to help them to focus their attention on the idea of dimensionality when they are teaching the concepts of perimeter and area of a plane figure. So the distinction between dimensionality and “directionality" should become part of (future) teachers' pedagogical content knowledge (Shulman, 1986). In other words, it is important that (future) teachers are aware of students' confusion between dimensionality and "directionality" when they are taking instructional decisions. Therefore teacher training programs should take this information into account to provide opportunities to (future) teachers to improve their pedagogical content knowledge about this delicate issue.

\section{Acknowledgement}

The research reported here has been financed in part by Ministerio de Educación y Ciencia, Dirección General de Investigación, Spain, under Grant no. EDU2011-27288 and in part by the University of Alicante under the birth project GRE10-10.

\section{References}

Anderson, N. H., \& Cuneo, D. (1978). The height and width rule in children's judgments of quantity. Journal of Experimental Psychology: General, 107, 335-378. 
Battista, M. T., Clements, D. H., Arnoff, J., Battista, K., \& Van Auken Borrow, C. (1998). Students' spatial structuring of 2D arrays of squares. Journal for Research in Mathematics Education, 29, 503-532.

Carpenter, T. P., Lindquist, M. M., Brown, C. A., Kouba, V. L., Silver, E. A., \& Swafford, J. O. (1988). Results of the fourth NAEP assessment of mathematics: Trends and conclusions. Arithmetic Teacher, 36(4), 38-41.

Cramer, K., Post, T., \& Currier, S. (1993). Learning and teaching ratio and proportion: Research implications. In D. T. Owens (Ed.), Research ideas for the classroom: Middle grades mathematics (pp. 159-178). New York: Macmillan.

De Bock, D., Verschaffel, L., \& Janssens, D. (1998). The predominance of the linear model in secondary school students' solutions of word problems involving length and area of similar plane figures. Educational Studies in Mathematics, 35, 65-83.

Esteley, C., Villarreal, M., \& Alagia, H. (2004). Extending linear models to non-linear contexts: An in-depth study about two university students' mathematical productions. In M. J. Høines \& A. B. Fuglestad (Eds.), Proceedings of the 28th Conference of the International Group for the Psychology of Mathematics Education (Vol. 2, pp. 343-350). Bergen, Norway: PME.

Fernández, Llinares, Van Dooren, De Bock, \& Verschaffel (2011). Effect of number structure and nature of quantities on secondary school students' proportional reasoning. Studia Psychologica, 53, 69-82.

Fernández, C., Llinares, S., Van Dooren, W., De Bock, D., \& Verschaffel, L. (2012). The development of students' use of additive and proportional methods along primary and secondary school, European Journal of Psychology of Education, 27, 421-438. 
Freudenthal, H. (1983). Didactical phenomenology of mathematical structures. Dordrecht/Boston/Lancaster: Reidel.

Gagatsis, A., Modestou, M. Elia, I., \& Spanoudes, G. (2009). Structural modeling of developmental shifts in grasping proportional relations underlying problem solving in area and volume. Acta Didactica Universitatis Comenianae, Mathematics, 9, 9-23.

Huang, H-M. (2010). The relationships between children's comprehension of multiplication and their understanding of perimeters and area measurement of rectangles. In M. M. F. Pinto \& T. F. Kawasaki (Eds.), Proceedings of the 34th Conference of the International Group for the Psychology of Mathematics Education (Vol. 3, pp. 113-120). Belo Horizonte, Brazil: PME.

Kalchman, M., \& Koedinger, K. R. (2005). Teaching and learning functions. In M. S. Donovan \& J. D. Bransford (Eds.), How students learn: Mathematics in the classroom (pp. 351-393). Washington DC: National Academy of Sciences.

Modestou, M., Gagatsis, A., \& Pitta-Pantazi, D. (2004). Students' improper proportional reasoning: The case of area and volume of rectangular figures. In M. J. Høines \& A. B. Fuglestad (Eds.), Proceedings of the 28th Conference of the International Group for the Psychology of Mathematics Education (Vol. 3, pp. 345-352). Bergen, Norway: PME.

Outhred, L., \& Mitchelmore, M. (1996). Children's intuitive understanding of area measurement. In L. Puig \& A. Gutierrez (Eds.), Proceedings of the 20th Conference of the International Group for the Psychology of Mathematics Education (Vol. 4, pp. 91-98). Valencia, Spain: PME.

Outhred, L., \& Mitchelmore, M. (2000). Young children's intuitive understanding of rectangular area measurement. Journal for Research in Mathematics Education, 31, 144-167. 
Rouche, N. (1989). Prouver: amener à l'évidence ou contrôler des implications? In Commission inter-IREM Histoire et Epistémologie des Mathématiques (Ed.), La démonstration dans l'histoire (pp. 8-38). Lyon: IREM.

Shulman, L. S. (1986). Those who understand: Knowledge growth in teaching. Educational Researcher, 15(2), 4-14.

Tierney, C., Boyd, C., \& Davis, G. (1990). Prospective primary teachers' conceptions of area. In G. booker, P. Cobb, \& T.M. di Mendicuti (Eds.), Proceedings of the 14th Conference of the International Group for the Psychology of Mathematics Education (Vol. 2, pp. 307-315). Mexico: PME.

Van Dooren, W., De Bock, D., De Bolle, E., Janssens, D., \& Verschaffel, L. (2003). Secondary school students' illusion of linearity: The role of direct versus indirect perimeter and area measures. Mediterranean Journal for Research in Mathematics Education, 2(2), 19-36.

Van Dooren, W., De Bock, D., Depaepe, F., Janssens, D., \& Verschaffel L. (2003). The illusion of linearity: Expanding the evidence towards probabilistic reasoning. Educational Studies in Mathematics, 53, 113-138.

Van Dooren, W., De Bock, D., Hessels, A., Janssens, D., \& Verschaffel, L. (2004). Remedying secondary school students' illusion of linearity: A teaching experiment aiming at conceptual change. Learning and Instruction, 14, 485-501.

Van Dooren, W., De Bock, D., Janssens, D., \& Verschaffel, L. (2008). The linear imperative: An inventory and conceptual analysis of students' overuse of linearity. Journal for Research in Mathematics Education, 39, 311-342. 
Vlahovic-Stetic, V., Pavlin-Bernardic, N., \& Rajter, M. (2010). Illusion of linearity in geometry: Effect in multiple-choice problems. Mathematical Thinking and Learning, 12, 54-67. 